\title{
Neurobehavioral aspects of postconcussive symptoms after mild head injury
}

Citation for published version (APA):

Bohnen, N., \& Jolles, J. (1992). Neurobehavioral aspects of postconcussive symptoms after mild head injury. Journal of Nervous and Mental Disease, 180(11), 683-692. https://doi.org/10.1097/00005053199211000-00002

Document status and date:

Published: 01/01/1992

DOI:

10.1097/00005053-199211000-00002

Document Version:

Publisher's PDF, also known as Version of record

\section{Please check the document version of this publication:}

- A submitted manuscript is the version of the article upon submission and before peer-review. There can be important differences between the submitted version and the official published version of record.

People interested in the research are advised to contact the author for the final version of the publication, or visit the DOI to the publisher's website.

- The final author version and the galley proof are versions of the publication after peer review.

- The final published version features the final layout of the paper including the volume, issue and page numbers.

Link to publication

\footnotetext{
General rights rights.

- You may freely distribute the URL identifying the publication in the public portal. please follow below link for the End User Agreement:

www.umlib.nl/taverne-license

Take down policy

If you believe that this document breaches copyright please contact us at:

repository@maastrichtuniversity.nl

providing details and we will investigate your claim.
}

Copyright and moral rights for the publications made accessible in the public portal are retained by the authors and/or other copyright owners and it is a condition of accessing publications that users recognise and abide by the legal requirements associated with these

- Users may download and print one copy of any publication from the public portal for the purpose of private study or research.

- You may not further distribute the material or use it for any profit-making activity or commercial gain

If the publication is distributed under the terms of Article $25 \mathrm{fa}$ of the Dutch Copyright Act, indicated by the "Taverne" license above, 


\title{
Neurobehavioral Aspects of Postconcussive Symptoms after Mild Head Injury
}

\author{
N. BOHNEN, M.D., PH.D., and J. JOLLES, PH.D.
}

\begin{abstract}
The sequelae of severe closed head injury have received much attention in the literature, but the effects of mild closed head injury (MHI) are less well established. There is a subgroup of patients who complain of persisting postconcussive symptoms (PCS) beyond the first weeks of recovery. Although the symptoms generally develop in the absence of clear neurological abnormalities, the condition of PCS can be chronic and disabling. It has been asstmed that PCS result from an interaction between organic and psychological factors. Differentiating between the effect of primary neurological injury and secondary psychosocial problems is often difficult for clinicians and engenders controversy. Neuropsychological, neurophysiological, and neuroimaging measures can be helpful in selecting patients at risk of developing PCS. Assessment of the level of cognitive functioning, individual susceptibility to stress, and environmental demands may be beneficial in treating symptomatic patients.

It is true that the vague and aspecific mature of the postconcussion syndrome may have given rise to the controversy over this entity, but the many methodological inconsistencies in the experimental approaches to the syndrome have certainly enhanced the confusion about this issue. The ensuing comtroversy surrounding research on the outcome of MHI and the postconcussion syndrome reflects ambiguities in definition, inconsistencies in criteria for patient selection, variation in procedures for neurobehavioral assessment, and difficulty in obtaining follow-up data.
\end{abstract}

- J Nerv Ment Dis 180:683-692, 1992

Mild head injury (MHI) has received much attention since the study by Rimel et al. (1981) alerted health professionals to the high morbidity associated with these injuries. In addition, it has become increasingly clear that minor head injuries are of great social and economic importance (Wrightson and Gronwall, 1980). Not only does their care in the acute stages load hospital services, but persistent symptoms can lead to vocational disability and problems in interpersonal relationships. Consequently, some patients become involved in litigation (Rutherford et al., 1979). The majority of hospital admissions for head trauma are due to MHI. An even greater number of MHI patients are admitted to casualty departments and are not hospitalized or even seen by medical personnel (Coonley-Hoganson et al., 1984).

Mild head injury can be defined in many ways, ranging from a loss of consciousness requiring hospitalization to lacerations of the scalp and face that clearly do not affect the brain. Rutherford (1989) defines concussion as an acceleration/deceleration injury to the head, which is almost always associated with a period of amnesia and followed by a characteristic group of symptoms, such as headache, poor memory, and vertigo. Russell"s (1971) classification of head injury is

Department of Neuropsychology and Psychobiology, University of Limburg, P.O. Box 616, $3200 \mathrm{MD}$ Maastricht, The Netherlands. based upon the duration of posttraumatic amnesia: mild head injury (amnesia less than 60 minutes), moderate head injury (amnesia more than 60 minutes, but less than 24 hours), and severe head injury (amnesia over 24 hours). Excessive intake of alcohol makes the estimation of postraumatic amnesia inaccurate and complicates the diagnosis in MHI (Galbraith et al., 1976). The study by Rimel et al. (1981) was a milestone in the development of diagnostic criteria to define a MHI. These authors defined MHI as a cranial trauma producing an initial loss of consciousness limited to 20 minutes or less, a Glasgow Coma Score over 13 to 15 on admission, and hospitalization for less than 48 hours. Nevertheless, there are patients who have incomplete amnesia and who experience only a short period of feeling dazed, but who nonetheless complain of postconcussive symptoms ([PCS] Rutherford et al. 1977). The model of Ommaya and Gennarelli (1974), which considers posttraumatic confusion as a minimal grade of concussion, is more appropriate for classifying these very mild types of head injury because the classification is not based upon the duration of posttraumatic amnesia.

The term "postconcussion syndrome" refers to at number of PCS that frequently occur after mild head injuries. PCS, which are based on self-reports, include memory impairment, difficulties in concentration, dizziness, reduced tolerance to light, sound and bustle, 
irritability, fatigue, anxiety, and headache (Binder, 1986). Vertigo, tinnitus, blurred vision, depression, sleep disturbance, decreased libido, and intolerance to alcohol have frequently been mentioned as well. Seizure disorders can be a sequel of all degrees of head trauma, as can psychiatric complications (Lishman, 1973; Merskey and Woodforde, 1972).

Unfortunately, the term postconcussion syndrome has not been consistently and clearly defined in the literature. Gronwall and Wrightson (1974) hypothesized that it is only when symptoms persist beyond the normal period of recovery that they emerge as the postconcussion syndrome. Lidvall et al. (1974) found that the symptoms differed in terms of severity over time. Headache and dizziness tended to cease with time, whereas anxiety and irritablity did not. In addition, Rutherford (1989) distinguishes early and late symptoms. Vomiting, nausea, drowsiness, and blurred vision are short-lived complaints. Late symptoms, such as irritability and intolerance to noise, appear later. The fact that PCS dlevelop along different time courses may reflect different. underlying pathologies. Only recently have new approaches toward the postconcussion syndrome acknowledged the heterogeneity of the entity (Hinkeldey and Corrigan, 1990; Van Zomeren and Van den Burg, 1985). By means of a factor analysis of data collected in structured interviews, Levin et al. (1987b) were able to isolate salient dimensions of PCS that can be used to identify subgroups of patients. Results revealed three clusters of patient groups: one cluster or patients with predominartly cognitive and affective symptoms, another with somatic symptoms, and a third with relatively mild or no PCS.

The aspecific and subjective nature of PCS causes researchers methodological difficulties when they try to quantify or conceptualize these complaints, and this has led to an ensuing controversy about the psychogenetic versus physiogenetic origin of the complaints (Binder, 1986; Lishman, 1988). The debate is fucled by different sources of controversy, such as inconsistencies in the definition of MHI, the problem of objective assessment of PCS, and issues related to the methodology and design of studies on the outcome of MHI.

\section{Historical Note}

Jacobson (1963) provides a good historical perspective on the development of the concept of a postconcussion syndrome. An important early work in this regard was Erichsen's (1886) book entitled On Concussion of the Spine, Nerwous Shock, and Other Obscure Injuries to the Nervous System. Concussion seems to have become a much more common occurrence since the industrial revolution in the early $19 t h$ century, and especially since the construction of extensive railway systems in the mid- to late 19th century (Regler, 1879). Consequently, the concept of the postconcussion syndrome attained prominence in the later decades of the 19 th century. It was also at this time that the rapid rise in the number of cases of real or fictitious posttraumatic disability that could not be diagnosed in a satisfactory way gave rise to controversies over medicolegal issues (for review, see Trimble [1981]; Levin, 1991). In the second half of the 20 th century, it became increasingly apparent that the clinical picture reflected a multifactorial state of affairs, in which organic, psychological, and socioeconomic factors could play a role (Benton, 1989; Kozol, 1946). Nonetheless, up to the late '70s, the prevailing view was that because there was no convincing evidence of an organic brain defect, the symptoms were psychogenic owing to the stress and insult of the accident, or feigned (Jonsson et al., 1967; Lidvall et al., 1974). The situation changed when it was recognized that the psychometry that had been used up to that time was not very sensitive to the effect of head injury (Gronwall and Wrightson, 1974; Hugenholtz et al., 1988). With the use of sensitive and appropriate neuropsychological tests, it became possible to demonstrate subtle deficits of attention and information processing. In addition, the application of new neuroimaging techniques, such as magnetic resonance imaging (Levin et al., 1987a) provided evidence of subclinical focal brain lesions, which made it clear that MHI may not be minor at all.

\section{Epidemiology of MHI and the Postconcussion Syndrome}

Traumatic brain injury is a condition occurring with a high incidence rate, varying between 130 and 208 hospitalizations per 100,000 inhabitants per year (Annegers et al., 1980; Jagger et al., 1984; Johnson and Gleave, 1987; Kraus and Nourjah, 1988). Not included in these numbers are MHI patients with slight concussion who are not hospitalized or seen by medical personnel (Coonley-Hoganson et al., 1984). Extrapolating from a Swedish study on the incidence of concussion in children (Rune, 1970) and a Dutch study of a representative sample of all concussed patients (Van 't Hooft, 1973), one might expect that about one third to one fourth of all concussed patients are admitted to a hospital. This would yield an overall incidence rate between 490 and 640 per 100,000 inhabitants. Depending on the strictness of criteria used to define head injury, the incidence ranges between 140 and 640 per 100,000 inhabitants (Levin et al., 1982). A relatively high incidence of traumatic head injury in young male adults has consistently been reported (Levin et al., 1982; Minderhoud and Van Zomeren, 1984). The difference in injury rates between men and women may be explained in part by differ- 
TABLE 1

Frequency of Late Posiconcussine Symptoms

\begin{tabular}{|c|c|c|c|c|c|c|c|}
\hline & $\begin{array}{l}1 \text { month } \\
(96)\end{array}$ & $\begin{array}{c}6 \text { weeks } \\
\text { (wo }\end{array}$ & $\begin{array}{c}3 \text { months } \\
(\%)\end{array}$ & $\begin{array}{c}6 \text { months } \\
(\%)\end{array}$ & $\begin{array}{c}1 \text { year } \\
\left(\mathrm{O}_{6}\right) \\
\end{array}$ & $\begin{array}{c}2 \text { years } \\
(\%)\end{array}$ & $\begin{array}{c}3 \text { years } \\
(\% 4)\end{array}$ \\
\hline Russell, 1932 & & & & 49 & & & \\
\hline Denker, 1944 & & & & & 33 & & 15 \\
\hline Jones, 1974 & 57 & & & & 1 & & \\
\hline Lidvall et al., 1974 & & & 24 & & & & \\
\hline Rutherford et al., 1977 & 51 & & & & & & \\
\hline Rutherford et al., 1979 & & & & & 14.5 & & \\
\hline Keshavan et al., 1981 & & & 47 & & & & \\
\hline Wrightson and Gronwall, 1980 & 20 & & & & & & \\
\hline Rimel et al., 1981 & & 84 & & & & & \\
\hline Jakobsen et al., 1987 & 29 & & & 15 & & & \\
\hline Mahon and Elger, 1989 & & 60 & & 21 & & & \\
\hline Middelboe et al., 1992 & & & & & $25-50$ & & \\
\hline
\end{tabular}

ences in alcohol consumption (Minderhoud and Van Zomeren, 1984).

Athough much is known about the incidence of traumatic head injury, less is known about the frequency and duration of PCS. For some time, the view was generally accepted that very few patients with minor head injury report PCS 1 month after injury. However, the view has been contradicted by studies of consecutive cases indicating that $\mathrm{PCS}$ are indeed reported for 1 year or longer after injury (Cartlidge, 1977; Rutherford et al., 1979). Estimates of the frequency of the persistent syndrome vary widely, from $20 \%$ to $80 \%$ (Jakobsen et al., 1987; Rimel et al., 1981; Rutherford 1989); see Table 1 for more details. This discrepancy may be due to methodological differences, such as the definition of MHI, the measures used to assess PCS, and the postinjury time (Dikmen et al., 1986ia; Rutherford, 1989). Levin et al. (1982) rightly commented that an exact count of PCS is difficult to make in a survey not assessing psychological impairments.

\section{Differential Diagnosis}

The principal differential diagnosis is of a neurotic reaction to head injury, i.e., an adjustment disorder with depressed and anxious mood (Robertson, 1988). Major depression may complicate the PCS. In addition, the postconcussion syndrome should not be confused with posttraumatic stress disorder. This syndrome refers to emotional symptoms of an unusually distressing event (Horowitz, 1986). Malingering must be considered in the differential diagnosis, especially when litigation is involved.

Lastly, the postwhiplash syndrome (Yarnell and Rossie, 1988) consists of a number of subjective complaints that can occur after a pure whiplash injury to the neck. The subjective symptoms bear striking similarities to those of the postconcussion syndrome, such as headache and easy fatigability. More specific for the postwhiplash syndrome are vestibular symptoms, neck pain, and cervical paresthesias. Although a pure cervical whiplash injury is not characterized by a direct physical impact to the head, evidence is accumulating to indicate that a cervical injury may indirectly damage subcortical brain structures (Boismare et al., 1985; Hinoki, 1985; Jacome, 1987). With this in mind, it is plausible that cervical whiplash trauma and concussion may damage common brain structures.

\section{Objective Measures of Assessment of MHI and PCS}

\section{Neurophysiological and Neuroimaging Measures}

An exact quantification of impairment is important, especially in view of medicolegal problems. Because clinical methods are not sensitive enough, neurophysiological and neuroimaging methods have been proposed as alternatives. Of the neuroimaging techniques, magnetic resonance imaging has proven to be superior to CT scanning for the detection of lesions that may be relevant for neurobehavioral outcome, especially in the frontotemporal region (Levin et al., 1985, 1987a; Wilson et al. 1988). There may be no role for the EEG in the objective assessment of PCS (see Binder [1986], for review). In addition, Schoenhuber and Gentilini (1989) could not confirm the optimistic initial reports on the usefulness of auditory brainstem evoked responses in MHI (Rowe and Carlson, 1980; MacFlynn et al., 1984; Noseworthy et al., 1981).

The psychophysical assessment of tolerance to light and sound is another objective measure to assess the outcome of MHI. Waddell and Gronwall (1984) demonstrated that MHI patients had a significantly lower threshold to light 1 to 3 weeks after injury than healthy subjects. Using a computerized method that measures both maximal and submaximal levels of reduced tolerance, Bohnen et al. (1991) found that MHI patients had a significantly decreased tolerance to sound stimuli over $71 \mathrm{db}$ and to light stimuli over 600 lux compared with nonconcussed controls 3 to 6 days after injury. 


\section{Newropsychological Measures}

Cognitive impairment is not uncommon after head injury (Tate et al., 1991), even when the injury has been minor and does not require inpatient assessment or management. Neuropsychological investigations have been carried out over the past few decades to evaluate behavioral and cognitive dysfunctions in patients with MHI. There is a great difference between the various neuropsychological studies with respect to the definition of MHI, the measures of assessment, and a number of methodological factors, such as the appropriateness of the control group and the characteristics of the control subjects for confounding factors. Unfortunately, many studies combine Russell's categories (1971) of mild and moderate head injury into a single category of "minor" head injury (Dikmen et al., 1986a; Ewing et al., 1980; McLean et al., 1983; McMillan and Glucksman, 1987; Middelboe et al., 1992).

Gronwall and Wrightson (1974) were two of the first researchers to suggest that a reduction in the capacity to process information could be an important factor in the genesis of the postconcussion syndrome. This reduction in information processing capacity has been used as a yardstick to measure the effect of MHI (Gronwall and Sampson, 1974; Gronwall and Wrightson, 1974).

Whereas gross deficits in intelligence or memory have not been reported in MIIH (Dilmen et al., 1986a; McLean et al., 1983), subtle deficits have been found (Gentilini et al., 1985). These deficits appear to selectively impair functions of attention and information processing and are most consistently seen with more complex and demanding tasks (Barth et al., 1983; Gentilini et al., 1989; Gronwall and Wrightson, 1974, 1981; Hugenholtz et al., 1988; MacFlynn et al., 1984; McMillan and Glucksman, 1987). Therefore, refined and selective neuropsychological testing is required to detect subtle posttraumatic attentional deficits (Binder, 1987; McMillan, 1985). For example, Gentilini et al. (1989) found significant differences between patients and controls on all tests from a battery devised specifically to explore different aspects of attention, including measures of divided, selective, sustained, and attributed attention. Although these symptoms occurred in the absence of clear neurological abnormalities, these subtle cognitive deficits may be sufficiently disabling that patients may have difficulty returning to or maintaining employment, significant disruption of social life, and an increased incidence of depression or somatic illness (Lishman, 1988).

With respect to the time course of recovery, the cognitive deficits are maximal in the first week after injury and tend to resolve spontaneously within 3 to 4 weeks in the majority of MHI patients (Levin et al., 1987d).
However, Leininger et al. (1990) found that symptomatic patients had deficits in tests of reasoning, information processing, and verbal leaming in comparison with uninjured control subjects 1 to 22 months after the injury. Evidence is accumulating to indicate that there is a subgroup of MHI patients with subjective disability who may present with persisting neuropsychological deficits (Dencker, 1958; Dikmen et al., 1989; Jakobsen et al., 1987; Leininger et al., 1990).

\section{Pathogenesis of Postconcussive Symptoms}

The pathogenesis of PCS has not been clearly established. Various avenues of investigation have been followed to explain the persistence of PCS. There is a striking disparity in the literature between those who argue for a psychogenic and those who argue for a physiogenic pathogenesis of the syndrome (Lishman, 1988).

\section{Psychological Evidence}

Psychological and motivational factors, especially litigation, have been cited as causes of continued PCS (Miller, 1961). The lack of correspondence between the severity of injury and the persistence of symptoms has been interpreted as support for a psychogenic etiology of PCS. It is clear that the emotional repercussions of a life-threatening accident may be immense. The patient may fear the consequences of concussion and worry about the long-term impact of early symptoms. Interruption of education or threats to a career can likewise have profound consequences on the patient's life (Lishman, 1988).

Apart from the direct emotional impact of concussion, Lishman (1988) lists evidence to indicate that a neurotic personality, a history of psychiatric illness, and demographic variables such as marital status are also important. A purely psychogenic viewpoint on the postconcussion syndrome is likely to consider the entity as a postiraumatic neurosis (e.g., Miller, 1961). As mentioned above, the development and persistence of PCS has been attributed to secondary gain, particularly monetary (Cook, 1972; Miller, 1961). Merskey and Woodforde (1972), however, found no relationship between difficulties expressed after MHI and litigation, resolved or pending. In addition, resolution of compensation claims does not result in rapid cessation of postconcussion sequelae (Steadman and Graham, 1970). Guthkelch (1980) reported a large series of 398 patients who all had compensation claims; in his biased population, only $6.8 \%$ were thought to have an accident neurosis or to be malingering. Alves et al. (1986) assert that health care professionals should admit that they have overestimated the incidence of malingering and have failed to recognize that few patients exaggerate PCS 
for personal gain. It seems unreasonable to insist that patients with $\mathrm{PCS}$ are engaged in an active attempt to defraud, even though a few such cases exist. Close observation of the behavior of the palient during neuropsychological testing and the use of clinical judgment remain the most powerful tools in the identification of malingering (Binder, 1986, McMahon and Satz, 1981; Varney-Nils, 1990). In addition, the more sensitive and accurate the neuropsychological tests and neuroimaging techniques become, the more likely that patients with posttraumatic brain dysfunction will be correctly identified.

\section{Organic Evidence}

Contrary to the view that emotional disturbances and/or motivation for compensation primarily contribute to the morbidity of minor head trauma, evidence produced in the last few decades supports an organic basis for the syndrome (Taylor, 1967). For example, Rutherford et al. (1977) found that headache, anosmia, and diplopia 24 hours after injury were associated with higher symptom rates 6 weeks after the injury. Numerous reports show that the rotational and shearing forces generated by head trauma result in neuronal damage (Holbourn, 1943; Oppenheimer, 1968; Povlishock et al., 1983; Strich, 1961). The difference between severe and mild head injury is one of degree in this respect: mild head injuries result in less extensive neuronal damage (Ommaya and Gennarelli, 1974). In addition, there is evidence of neuropathological and neurophysiological alterations after these injuries, including neuronal damage, reduced cerebral blood flow, disturbances in water metabolism, altered brainstem-evoked potentials, neurotransmitters, brainstem dysfunction, and reduced speed of information processing (Baron et al., 1979 ; Bohnen et al., 1990b; Gronwall and Wrightson, 1974; Noseworthy et al., 1981; Oppenheimer, 1968; Rowe and Carlson, 1980; Schoenhuber and Gentilini, 1986; Taylor and Bell, 1966). Sekino et al. (1981) found that $7.6 \%$ of $171 \mathrm{MHI}$ patients who had been unconscious for less than 10 minutes had small lesions on CT scans. New neuroimaging techniques, such as magnetic resonance imaging, have disclosed the presence of orbitofrontal-temporal intracranial lesions in MHI patients with prominent memory problems (Levin et al., $1987 \mathrm{~b})$.

\section{The Interaction Concept}

It has become increasingly clear that both a purely psychogenic and a purely organic viewpoint have serious shortcomings in explaining the occurrence of persistent PCS (Rutherford, 1989). For example, the development and exacerbation of symptoms weeks or months after MHI, as noted by Lidvall et al. (1974), is difficult to explain on an organic basis. In addition, given the increasing amount of organic evidence, a purely psychogenic interpretation of $\mathrm{PCS}$ is also untenable.

Many years ago, Symonds (1942) suggested that the etiology of PCS was cerebral damage, but that a symptomatic expression of PCS depended upon a psycholog. ical interaction with the neurological damage. He wrote that physiogenic and psychogenic factors were so closely intertwined that it would be unnatural to separate them. This interaction concept is now widely supported (Long and Novack, 1986). Multiple factors, such as pre-, peri-, and post-traumatic factors, and their interaction are probably responsible for the variability seen among patients with head injury (Dikmen et al., 1986b; 1989; Lishman, 1988). Lishman (1988) suggested that organic factors were chiefly relevant in the earlier stages, whereas persistent symptoms may be perpetuated by secondary neurotic developments.

Conflicting data are reported as to what factors predict the persistence of PCS after MHI. Age, sex, and duration of posttraumatic amnesia may be of relevance (Denker, 1944; Minderhoud et al., 1980; Rutherford et al., 1977), but other studies report a lack of correlations between these prognostic factors and the persistence of PCS (Dikkmen et al., 1989; Jakobsen et al., 1987; Mahon and Elger, 1989). Posttraumatic amnesia has proven to be a reliable predictor of the outcome of head injury when applied to a population of patients with a broad range of severity of head injury (Keshavan et al., 1981; Levin et al., $1987 \mathrm{c}$; Rutherford, 1989; Van Zomeren and Van den Burg, 1985). With respect to selected populations of MHI patients, the duration of posttraumatic amnesia is difficult to assess reliably if it is less than 1 hour (Gronwall and Wrightson, 1980; McMillan and Glucksman, 1987; Rutherford et al., 1989). Consequently, most studies do not report a consistent relationship between the duration of posttraumatic amnesia and the persistence of PCS after MHI (Barth et al., 1983; Gronwall and Wrightson, 1980; Leininger et al., 1990; Lidvall et al., 1974; MacFlynn et al., 1984). Although the evidence is not very strong, there are indications that elderly and less well-educated subjects may be more vulnerable to protracted symptomatology after MHI (Barth et al., 1983; Coonley-Hoganson et al., 1984; Denker, 1944; Dikmen et al., 1989; Pentland et al., 1986). Studies on the relationship between age and postraumatic symptoms should include a sufficient number of elderly in the patient population. For example, Rimel et al. (1981) reported that older patients had a better prognosis than younger patients, but the percentage of subjects older than 60 years in this study was only $4 \%$.

It has been shown that multiple concussions may have a cumulative effect in that they delay the cognitive 
and subjective recovery from a new head injury (Gronwall and Wrightson, 1975).

PCS and Environmental Demands:

The Coping Hypothesis

Besides the possibility that an underlying cerebral dysfunction could manifest itself in the presence of PCS, Van Zomeren and Van den Burg (1985) proposed the coping hypothesis as an alternative explanation. The coping hypothesis asserts that PCS (in their terms, "intolerance" or "neurotic" types of complaints) may result from a chronic effort made by patients to compensate for cognitive deficits. According to the coping hypothesis, it is when the patient is confronted with the stresses and strains of life that PCS develop. "The fatigue and stress involved in attempting to deal with environmental demands may exacerbate certain PCS, such as headache and dizziness (Long and Novack, 1986). For example, a patient who is lying quietly in bed is unlikely to develop complaints of irritability or intolerance to noise (Rutherford, 1989). A rapid resumption of premorbid activities, resulting in stress when the patient's cognitive capacities prove deficient, may account for the increased incidence of PCS in MHI patients returning to school or work (Gronwall and Wrightson, 1974; Wrightson and Gronwall, 1980).

\section{Treatment of Patients with Postconcussive Symptoms}

MHI patients have been largely ignored from a rehabilitation point of view (Ponsford, 1990). There continues to be too much emphasis on assessment, and not enough on intervention to ameliorate the postconcussive difficulties of head injury victims. At present, patients treated in emergency rooms or hospitalized for MHI are typically given minimal or no instructions concerning the risk for development of neurobehavioral sequelae. After MHI, the patient is often advised to rest for a short time before resuming activities, and is released from medical care. According to Long and Novack (1986), the patient should not be expected to resume premorbid activities when cognitive functioning hinders performance and results in a significantly diminished efficiency. Treatment planning for patients with MHI should begin with cognitive and stress evaluation. Cognitive test results are useful in developing individualized rehabilitation programs and determining when individuals are prepared to resume vocational or academic routines (Gronwall, 1986; Levin, 1990). The development of more adaptive coping strategies could be an important component of treatment programs in MHI patients (Bohnen et al., in press). In addition, an educational pamphlet for MHI patients may be an important factor in lowering stress, anxiety, and frustra- tion during recovery, relieve symptoms, and, therefore, facilitate the recovery process (Mahon and Elger, 1989; Relander et al., 1972). Supportive treatment, including early mobilization, and physical therapy can shorten disability (Minderhoud et al., 1980; Relander et al., 1972). Treatment with analgesic or tranquilizing medications may provide only a short-term symptomatic relief. It is, however, most important to identify persons at high risk for persistent PCS because these persons should receive more intensive preventive work (Gronwall, 1986).

\section{Methodological Issues Surrounding the Outcome of MHI}

It is clear that studies on the outcome of mild head injury and postconcussive symptoms are beset with many methodological problems. Most studies performed on MHI so far differ markedly with regard to a range of significant parameters. The following points of ambiguity and methodological inconsistencies have to be considered in the evaluation of research results on the outcome of MHI.

\section{Ambiguities of Definition of MHI in Terms of Severity, Type of Injury, and Medical Complications}

Inconsistencies in criteria for patient selection. There are great differences between studies with respect to the definition of patient populations in terms of selection criteria. Patients with focal neurological deficits should be excluded from studies on uncomplicated MHI. In addition, patients with traumatic noncerebral complications (e.g., orthopedic injuries) should be considered as a separate subgroup. Factors to be controlled include hospitalization, surgery, medication, and type of injury. The selection of consecutive admissions (Dikmen et al., 1986a) as opposed to cases seen for clinical reasons. These sources of selection bias of patient samples are reviewed by Dikmen and Temkin (1987).

\section{The Confounding Effects of Pre-existing Conditions and Sociocultural Variables.}

Civilian head injury occurs in a nonrandom sample part of the population (Levin et al., 1987b). The confounding effects that can potentially obscure the effects of MHI include a history of head injury, neurological disease, neuropsychiatric disorder, alcoholism, and drug abuse. The three-center study by Levin and colleagues disclosed an immense contribution of sociocultural factors to neurobehavioral performance, despite the subjects' having a similar educational background (Levin et al., 1987d). 
Variation in Procedures for Neurobehavional Assessment and the Etiological Factors Chosen for Scrutiny.

There is a lack of uniform and objective diagnostic criteria for defining a postconcussion syndrome. By lack of clear neurological parameters, neuropsychological measures have been used mostly as objective criteria for the evaluation of patients with persistent PCS. Because the cognitive deficits after MHI may be subtle and may be better detected with more demanding tasks of attention and information processing (Hugenholtz et al., 1988), it is clear that cognitive criteria are arbitrary and depend upon the selection and sensitivity of a particular task. The measures chosen for a study must be most sensitive to the presence of cognitive correlates of the pathological changes known to occur in MHI (Binder, 1987). Most studies of MHI patients performed so far have been limited mostly to the study of a single diagnostic measure, and few studies have reported the serial psychological testing of patients with MHI (Hugenholtz et al., 1988; Levin et al., 1987d; MacFlynn et al., 1984). Apart from neuropsychological measures, neurophysiological and neuroimaging measures should be applied for a more comprehensive assessment. Measures of psychological outcome can be used to assess primary and secondary emotional repercussions of the trauma. It should be noted that most researchers do not distinguish between patients who are merely inconvenienced and those who are disabled by their symptoms. The severity of the PCS has often been expressed as the total number of different symptoms per patient (Rutherford et al., 1977). It will be clear that this is a rather rough measure, the validity and reliability of which can be questioned. More reliable and valid approaches may be quantitative assessment of complaints by means of neurobehavioral rating scales (Levin et al., 1987c).

\section{Appropriateness of Control Group}

Most studies have tended to rely on normal uninjured control subjects for assessment, rather than directly comparing patients with and without PCS following head injury (Lishman, 1988). It is evident that uninjured control subjects can only provide information about an overall effect of MHI, but are less adequate to provide insight into the factors underlying PCS. A comparison group should also control for all prognostic factors related to the specific research questions, such as education, intelligence, personality, sociocultural background, and premorbid level of functioning.

\section{Timing of the Study}

The vast majority of etiological investigations have been carried out during the early postinjury phase, most within several weeks of the injury. Studies that cover a longer interval have often had difficulties with followup. The longer that PCS persist after the accident, the more evidence there is that nonorganic factors play a part. Complaining patients studied shortly after the accident will form a different population from those still complaining after several months or years (Lishman, 1988). Therefore, the time from injury to evaluation is an important factor in the evaluation of PCS.

\section{Environmental Conditions and Levels of Stress}

According to the coping hypothesis, inadequate coping ability and response to cognitive impairment may enhance stress reactions when environmental demands are too high (Long and Webb, 1983; Van Zomeren and Van den Burg, 1985). Studies on the pathogenesis of persistent PCS should consider these factors as well as the level of overall work load and type of ability under consideration.

\section{The Presence of Compensation Claims and Litigation}

Although there is no empirical evidence that PCS are caused by the claims process, litigation and compensation claims are an additional stressor and may contribute to the symptomatology of some patients (Binder, 1986).

Taken together, our knowledge of the PCS is still quite fragmentary and not adequate to reconcile the contradictory information that has begun to emerge (Dikmen et al., 1989). The multifactorial pathogenesis of PCS warrants a multidiagnostic approach with objective tests. Ideally, all etiological factors should be measured simultaneously and at repeated intervals during recovery to assess their relative value and, most importantly, how they might sometimes operate in conjunction with one another (Lishman, 1988).

\section{Discussion}

The essential point to be made about PCS is that severall factors contribute to their development (Dikmen et al., 1986a; Lishman, 1988). Each individual, then, needs to be evaluated for the contribution of these factors (Dikmen et al., 1986b). It is important to realize that an MHI is often not an isolated injury, but cornmonly occurs with a further injury to the head, skull, or meck. Other physical darnage, particularly to the vestibular apparatus, can dictate important symptoms without being obvious. Vestibular concussion can cause posttraumatic vertigo with complaints of persistent dizziness or vertigo as well as tinnitus or hearing loss (Healy, 1982). Head injuries may occur with neck trauma (Michael et al., 1989). Cervical strain(s), disc disease, or exacerbation of pre-existing spondylosis 
may result. It is not surprising that these possibilities are often overlooked in the assessment of patients with head trauma. X-rays may be normal despite considerable cervical strain, and standard vestibular assessment and electronystagmogram may miss perilymphatic fistulas or cupulolithiasis of the verticular semicircular canals (Grimm et al., 1989). In addition, some patients may develop, for the first time, typical migraines or experience an exacerbation of pre-existing migraine after head trauma (Haas and Lourie, 1988). It is also important to note that the range of symptoms encompassed by PCS may be seen even where there has been no immediate loss of consciousness. In such cases, the term posttraumatic syndrome may be preferable.

The pendulum of the debate on PCS has swung between physiological and psychological theses. What the debate has tended to lack is an acknowledgment that the population of patients with PCS may not be homogeneous. There are MHI patients who experience difficulties whenever environmental demands exceed their cognitive capacities for dealing effectively with these demands (Long and Novack, 1986). Patients often respond with an increased effort as a means of attaining their premorbid work output that results in rapid fatigue (Gronwall and Wrightson, 1974). It has been suggested that cognitive performance can further deteriorate over time in cases when there are high levels of: stress and emotional repercussions after the injury (Gronwall and Wrightson, 1974). Bohnen et al. (1990a) demonstrated that deficits in divided attention are related to elevated levels of salivary cortisol in healthy nonconcussed subjects. This may shed new light on the pathogenesis of posttraumatic cognitive deficits. Although cognitive deficits are currently interpreted as having a purely organic origin, it is also conceivable that stress reactions and mood disturbances may further compromise cognitive efficiency after the injury (Levin et al., 1987b).

It may be clear that there is no place for dualistic thinking in the paradigm of MHI today. Even in the case of organic abnormalities, the symptoms of PCS provide the ideal nexus for neurotic elaboration because of the subjective nature of the syndrome. Further research is needed to establish the etiology of the persistence of PCS. Neuroimaging may have far-reaching consequences for our current classification of MHI (Williams et al., 1990). Characterizing the type of brain injury by magnetic resonance imaging could differentiate mild diffuse brain injury from MHI associated with occult intracranial lesions.

\section{References}

Aves WM, Colohan A, OLeary TJ, Rimel RW, Jane 』 (1986) Understanding postraumatic symptoms after minor head injury. J Head Tranma Rehabil 1:1-12.
Annegers JF, Grabow JD, Kurland LT, Laws ER Jr (1980) The incidence, causes, and secular trends of head tramna in olmstead County, Minnesola 1935-1974. Neurology 30:912-919.

Baron JB, Tangapregassom M.J, Ushio N, Debai A, Ponet J (1979) Neurotransmitter dysregulation related to the orthostatic postural activity disorders in case of postconcussive symdrome after head or whiplash injuries. Int I Neurot 12:237-249.

Barth JT, Macciocchi SN, Giordani B, Rimel R, Jane J, Boll "ThJ (1983) Neuropsychological sequelae of minor head injury. Neurosurgery 17:529-533.

Benton AL (1989) Historical notes on the postconcussion syndrome. In HS Levin, HM Eisenberg, AL Benton (Eds), Mild head injury (pp. 3-7). New York: Oxford University Press.

Binder LM (1986) Persisting symptoms after mild head injury: A review of the postconcussive syndrome. J Clin Exp Newropsychol 8:323-346.

Binder LM (1987) Neurobehavioral recovery after mild head injury (Letter). I Neunosurg 67:785-786.

Bohnen $N$, Houx $P$, Nicolson $N$, Jolles J (1990a) Cortisol reactivity and cognitive performance in a continuous mental task paradigm. Biol Psychol 31:107-116.

Bohnen N, Twijnstra A, Jolles J, Mellink R, Sulon J (in press) Coping styles, cortisol reactivity, and performance in a vigilance task of patients with persistent postconcussive symptoms after a mild head injury. Int Neurosci.

Bohnen N, Twijnstra A, Kroeze J, Jolles d (1991) A psychophysical method for assessing visual and acoustic hyperaesthesia in patients with mild head injury. Br I Psychiatry 159:860-863.

Bohnen $\mathbb{N}$, Twijnstra A, Terwel $D$, Jolles $J$ (1990b) Csf argininevasopressin decreases during dehydration in a patient with posttraumatic diabetes insipidus. Horm Metab Res 22:508-509.

Boismare F, Boquet J, Moore N, Chretien P, Saligaut $\mathrm{C}_{2}$ Daoust M (1985) Hemodynamic, behavioral, and biochemical disturbances induced by an experimental cranio-cervical injury (whiplash) in rats. I Auton Nerv Syst 13:137-147.

Cartlidge NEF (1977) Postconcussive syndrome. Scott Med J 23:103.

Cook JB (1972) The postconcussional symdrome and factors influencing recovery after minor head injury admitted to the hospital. Scand I Rehab Med 4:27-30.

Coonley-Hoganson R, Sachs $N$, Desai B'T, Whitman $S$ (1984) Sequelae associated with head injuries in patients who were not hospitalized: A follow-up survey. Neurosurgery 14,315-317.

Dencker SV (1968) A follow-up study of 128 closed head injuries in twins using co-twins as controls. Acta Psychiotr Neurol Scand 33 (Suppl 123): $1-125$.

Denker PG (1944) The postconcussion syndrome: Prognosis and evaluation of the organic factors. NY State Med J 44:379-384.

Dikmen S, McLean A, Temkin $\mathbb{N}$ (1986a) Neuropsychological and psychosocial consequences of minor head injury. INewrol Newrosurg Psychiatry 49:1227-1232.

Dikmen S, McLean A, Temkin NR (1986b) Neuropsychologic outcome at one-month postinjury. Arch Phys Med Rehabil 67:507-513.

Dikmen S, Temkin N (1987) Determination of the effects of head injury and recovery in behavioral research. In HS Levin, o Grafman, HM Eisenberg (Eds), Neurobehavioval recovery from head injury (pp. 78-87). New York: Oxford University Press.

Dikmen S, Temkin $N$, Arrmsden G (1989) Neuropsychological recovery: Relationship to psychosocial functioning and postconcussive complaints. In HS Levin, HM Eisenberg, AL Benton (Eds), Mild head infury (pp. 229-241). New York: Oxford University Press.

Erichsen JD (1886) On concussion of the spine, nevous shock, and other obscure injuries to the nervous system. Baltimore: William Wood \& Co.

Ewing R, McCarthy D, Wrightson $P$ (1980) Persisting effects of minor head injury observable during hypoxic stress. I Clin Newropsychol 2.147-155.

Galbrait] S, Murray WR, Patel AR, Knill-Jones $\mathrm{R}$ (1976) The relationship between alcohol and injury and its effect on the conscious level. Br. s Surg 63:128-130.

Gentilini M, Nichelli P, Schoenhuber R (1989) Assessment of attention in mild head injury. In HS Levin, HM Eisenberg, AL Benton (Eds), Mild head injury (pp. 163-175). New York: Oxford University Press. 
Gentilini M, Nichelli $\mathbb{P}$, Schoenhuber $\mathbb{R}$, Bortolotti $P$, Tonelli $L$, Falasca A, Merli GA (1985) Neuropsychological evaluation of mild head injury. I Neunol Newtasurg Psychatmy 48:137-140.

Grimm RG, Heminway $W G$, Libray PR, Black FO (1989) The perilymph fistula syndrome defined in mild head trama. Acta Otolarymgol /Suppl/464:1-40.

Gronwall $\mathbb{D}$ (1986) Rehabilitation programs for patients with mild head injury: Components, problems, and evaluation. I Head Trauma Rehabil 1:53-63.

Gronwall D, Sampson H (1974) The psychologicat effects of head injury. Auckland: University Press.

Gronwall D, Wrightson P (1974) Delayed recovery of intellectual function after minor head injury. Lancet 2605-609.

Gronwall $D$, Wrightson $\mathrm{P}$ (1975) Cumulative effects of concussion. Lancet 2:995-997.

Gronwall $\mathrm{D}$, Wrightson $\mathrm{P}$ (1980) Duration of posttraumatic armesia after mild head injury of Clin Neuropsychol $2: 51-60$.

Gronwall D, Wrightson P (1981) Memory and information processing capacity after minor head injury. I Newrol Neurosurg Psychiatry $44: 889-895$

Guthkelch A (1980) Postraumatic amnesia, postconcussive symptoms, and accident neurosis. Acta Neurochir 28:120-123.

Haas DC, Lourie H (1988) Trauma-triggered migraine: An explanation for common neurological attacks after mild head injury. I Newrosurg $68: 181-188$.

Healy GB (1982) Hearing loss and vertigo secondary to head injury. N Engl I Med 306:1029-1031.

Hinkeldey NS, Corrigan JD (1990) The structure of head-injured patients' neurobehavioral complaints: A preliminary study. Brain Injury 4:115-133.

Hinoki M (1985), Vertigo due to whiplash injury: A neurobiological approach. Acta Otoluryngol [Suppl] 419:9-29.

Holbourn AHS (1943) Mechanics of head injuries. Lancet 2:438-441.

Horowitz MJ (1986) Stress-response syndromes: A review of posttraumatic stress and adjustment disorclers. Hosp Community Psychiatry $37: 241-249$.

Hugenholtz H, Stuss DT, Stethem LL, Richard MT (1988) How long does it take to recover from a mild concussion? Neurosurgery $22.853-858$.

Jacobson SA (1963) The postroumatio symdrome following head injury. Springfield, IL: Charles C. Thomas.

Jacome DE (1987) EEG in whiplash. A reappraisal. Clin Electraencephalogr 18:41-45.

Jagger J, Levine II . Jane JA, Rimel $\mathbb{R W}$ (1984) Epidemiologic features of head injury in a predominantly rural population. $J$ Tranma $24: 40-44$

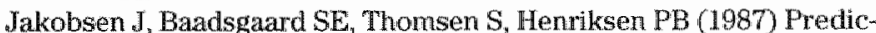
tion of postconcussional sequelae by reaction time test. Acta Neurol Scand 75:341-345.

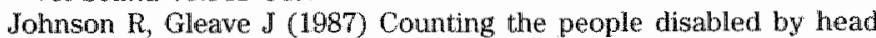
injury. Injury 18:7-9.

Jones RK (1974) Assessment of minimal head injuries: Indication for in-hospital care. Surg Neurol 2:101-104.

Jonsson C-O Lidvall H, Mallhammer G (1967) An exploratory psychological study of the posttraumatic cerebral syndrome. Acta Neurol Scand 43:158-166.

Keshavan MS, Channabasavannah SM, Reddy GN (1981) Posttraumatic psychiatric disturbances: Pattems and predictors of outcome. $B \gamma^{\prime}$ J Psychiatry 138:157-160.

Kozol HL (1946) Pretranmatic personality and psychiatric sequelae of head injury. Arch Newrol Psychiatry 56:245-275.

Kraus JF, Nourjah P (1988) The epidemiology of mild, uncomplicated brain injury. I Trauma 28:1637-1643.

Leininger BE, Gramling SE, Farrell AD, Kreutzer JS, Peck EA II (1990) Neuropsychological deficits in symptomatic minor head injury patients after concussion and mild concussion. $J$ Neurol Neurosurg Psychiatry 53:293-296.

Levin HS (1990) Cognitive rehabilitation. Unproved but promising. Arch Neurol 47:223-224.

Levin HS (1991) Pioneers in research on the behavioral sequelae of head injury. I Clin Exp Neuropsychol 13:138-154.

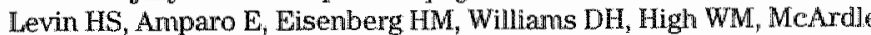
CB, Weiner RL (1987a) Magnetic resonance imaging and computer- ized tomography in relation to the neurobehavioral sequelae of mild and moderate head injury. of Neurosurg 66:706-713.

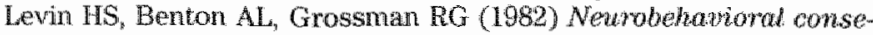
quences of closed head impuy. New York: Oxford University Press.

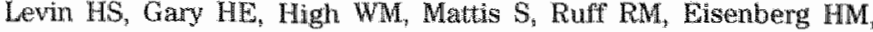
Marshall LF, Tabaddor $K$ ( $1987 b$ ) Minor head unjury and the postconcussive syndrome: Methodological issues in outcome studies. In HS Levin, I Grafman, HM Eisenberg (Eds), Neurobehavioral recovery from head injury (pp. 262-275). New York Oxford University Press.

Levin HS, Handel SF, Goldman AM, Eisenberg HM, Guinto FC (1985) Magnetic resonance imaging after "diffuse" nonmissile head injury. Arch Neurol 42:969-968.

Lewin HS, High WM, Goethe K, Sisson RA, Overall JE, Rhoades HM, Eisenberg HM, Kalisky ZVI, Gary HE (1987c) The neurobehavioral rating scale: Assessment of the behavioral rating scale of head injury by the clinician. I Neurol Neurosurg Pswchiatry 50:183-193.

Levin HS, Mattis S, Ruff RM, Eisenberg HM, Marshall LF, Tabaddor K, High WM, Frankowski RF (1987d) Neurobehavioral outcome following minor head injury: A three-center study. I Neurosury $66: 234-243$

Lidvall $\mathrm{HF}$, Linderoth $\mathrm{B}$, Norlin $\mathrm{B}$ (1974) Causes of the postconcussive symdrome. Acta Neurol Sochd 50(Suppl 56):1-144.

Lishman WA (1973) The psychiatric sequelae of head injury: A review. Psychol Med 3:304-318.

Lishman W (1988) Physiogenesis and psychogenesis in the "postconcussional symdrome." Br \& Psychialmy 158:460-469.

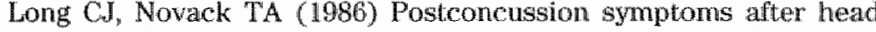
trauma: Interpretation and treatment South Med I 79:728-732

Long CJ, Webb WL (1983) Psychological sequelae of head trauma. Psychiatr Med 1:35-71.

Macllynn G, Montgomery EA, Fenton GW, Rutherford W (1984) Measurement of reaction time following minor head injury. I Newrol Neurosury Psychiakry 4:1326-1331.

Mahon D, Elger C (1989) Analysis of posttraumatic syndrome following a mild head injury. I Neurosci Nurs $21: 382-384$.

Mclean A, Temkin $N \mathbb{R}$, Dikmen $S$, Wyler AR (1983) The behavioral sequelae of head injury. $J$ Clin Neuropsyohol $5.361-376$.

McMahon EA, Satz P (1981) Clinical neuropsychology: Some forensic applications. In SJ Fiskov, TJ Boll (Eds), Randbook of alimical neuropsyckology (pp. 686-701). New York: Wiley.

MoMilan TM (1985) Neuropsychological evaluation of mild head injury (Letter). J. Neurol Neurosurg Psychiatry 48:847-848.

McMillan TM, Glucksman EE (1987) The neuropsychology of moderate head injury. \& Neurol Neurosury Psychialry 50.393-397.

Merskey H, Woodforde dM (1972) Psychiatric sequelae of minor head injury. Broin 95:521-528.

Michael DB, Guyot DR, Damody WR (1989) Coincidence of head and cervical spine injury. \& Newrotrawna 6:177-189.

Middelboe T, Andersen HS, Birket-Smuth M, Fris ML (1992) Minor head injury: Impact on general health after 1 year. A prospective follow-up study. Acta Neund Scand 85:5-9.

Miller H (1961) Accident neurosis. Br Med J 1:919-925.

Minderhoud JM, Boelens MEM, Huizenga J, Saan RJ (1980) Treatment. of minor head injuries. Clin Neurol Neurosury 82:127-140.

Minderhoud JM, van Zomeren AH (1984) Trawmahische hersenletsels. Utrecht: Bohn, Scheltema \& Holkema.

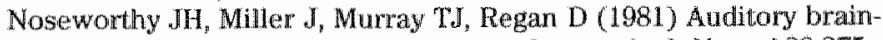
stem responses in postconcussion syndrome. Arch Neurol 38:275278.

Ommaya AK, Gennarelli TA (1974) Cerebrall concussion and traumatic unconsciousmess. Brain 97:633-654.

Oppenheimer DR (1968) Microscopic lesions in the brain following head injury. of Neurol Newrosurg Psychialry 31:299-306.

Pentland B, Jones PA, Roy CW, Miller JD (1986) Head injury in the elderly. Age Ageing 15:193-202.

Ponsford J (1990) Psychological sequelae of closed head injury: "Time to redress the imbalance. Broin Inj 4:111-114

Powlishock JT, Becker DP, Cheng CLY, Vaughan GW (1983) Axonal change in minor head injury. I New ropathol Exp Neurol $42: 225-242$.

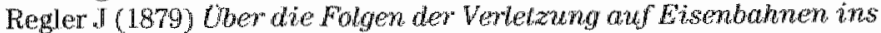
besondere der Verletzungen des Ruckenmaws. Berin: G. Reimes.

Relander M, Troup HH, Bjorkesten G (1972) Controlled trial of treat- 
ment for cerebral concussion. $\mathrm{Br}$ Med I $4: 777-779$

Rimel RW, Giordani B, Barth JT, Ball IT, Jante J (1981) Disability caused by minor head injury. Newrosargery 9:221-228.

Robertson A (1988) The postconcussive syndrome then and now. Aust $N$ Z ir Psychiatry 22:396-403.

Rowe MJ, Carlson C (1980) Brainstem auditory evoked potentials in postconcussion dizainess. Arch Newrol 37:670-683.

Rune V (1970) Acute head injuries in children. A retrospective, epidemologic, and electroencephallographic study on primary school children in Umea. Acta Paediatr Scand 2093-12.

Russell WR (1932) Cerebral involvement in head injury. Brain 55:549-603.

Russell WR (1971) The thatmatic ammesias. Oxford: Oxford University Press.

Rutherford WH, Merrett ID, MCDonald JR (1977) Sequelae of concussion caused by minor head injuries. Lancet $1: 1-4$.

Rutherford WH, Merrett JD, McDonald JR (1979) Symptoms at one year following concussion from minor head injunies. Injury 10:225230 .

Rutherford WH (1989) Postconcussion symptoms: Felationship to acute neurological indices, individual differences, and circumstances of injury. In HS Levin, HM Eisenberg, AL Benton (Eds), Mid head injury (po. 217-228). New York: Oxford University Press.

Schoenhuber $\mathrm{R}$, Gentilini $M$ (1986) Auditory brainstem responses in the prognosis of late postconcussive symptoms and neuropsychological dysfunction after minor head injury. Newroswrgery 19:532534.

Schoenhuber $\mathrm{R}$, Gentilini $\mathrm{M}$ (1989) Neurophysiological assessment of mild head injury. In HS Levin, HM Eisenberg, AL Benton (Eds), Mild head injury (pp. 142-150). New York: Oxford University Press:

Selkino H, Nakamura N, Yuki K, Satoh J, Rikuchi K, Sanada S (1981) Bitun lesions detected by CT-scans in cases of minor head injuries. Netrol Med Chit 21:677-683.
Steadmand, Gratham J (1970) Rehabilitation of the brain-injured. Proe R Soc Med 63:23-27.

Strich SJ (1961) Shearing of nerve fibers as a cause of brain damage due to head injury. Lancet 2:443-448.

Symonds CP (1942) Discussion of differential diagnosis and treatment of postconcussional states. Proc R Soc Med 35:601-607.

Tate RL, Fenelon B, Manming ML, Hunter M (1991) Patterns of neuropsychological impaiment after severe blunt head injury. \& Nerv Ment Dis 179.117-126.

Taylor AR (1967) Post-concussional sequelae. Br Med J 3:67-71.

Taylor AR, Bell TK (1966) Slowing of cerebral circulation after concussional head injury. Lancet 2:178-180.

Trimble MR (1981) Postmawmatic neurosis: From railway spine to the whiplash New York: Wiley.

Van" $\mathrm{t}$ Hooft $\mathrm{F}$ (1973) Behandeling wan patienten met een commotio cerebri. Doctoral dissertation. University of Utrecht, "The Netherlands.

Van Zomeren A.H, Van den Burg W (1985) Residual complaints of patients two years after severe head injury. I Neural Neutosurg Psychiatry 48:21-28.

Varney-Nils $R$ (1990) Litigation concerning mild head injury. CogniWive Rehabititation 8:30-33.

Warddell PA, Gronwall DMA (1984) Sensitivity to light and sound following minor head injury. Acta Neurol Scand 69:270-276.

Willians DH, Levin HS, Eisenberg HM (1990) Mild head injury classification. Neurosurgery $27: 422-428$.

Wilson JTL, Wiedmann KD, Hadley DM, Condon B, Teasdale G, Brooks DN (1988) Early and late magnetic resonance imaging and neuropsychological outcome after head injury. of Newnol Neursurg Psychialry 51:391-396.

Wrightson P, Gronwall D (1980) Time off work and symptoms after minor head injury. Injwry 12:445-454.

Yarnell PH, Rossie GV (1988) Minor whiplash head injury with major debilitation. Brain $\operatorname{Ing} 2: 255-258$. 